\title{
Complications and pitfalls of lumbar interlaminar and transforaminal epidural injections
}

\author{
Bradly S. Goodman · Lyle W. F. Posecion • \\ Srinivas Mallempati · Matt Bayazitoglu
}

Published online: 15 August 2008

(C) Humana Press 2008

\begin{abstract}
Lumbar interlaminar and transforaminal epidural injections are used in the treatment of lumbar radicular pain and other lumbar spinal pain syndromes. Complications from these procedures arise from needle placement and the administration of medication. Potential risks include infection, hematoma, intravascular injection of medication, direct nerve trauma, subdural injection of medication, air embolism, disc entry, urinary retention, radiation exposure, and hypersensitivity reactions. The objective of this article is to review the complications of lumbar interlaminar and transforaminal epidural injections and discuss the potential pitfalls related to these procedures. We performed a comprehensive literature review through a Medline search for relevant case reports, clinical trials, and review articles. Complications from lumbar epidural injections are extremely rare. Most if not all complications can be avoided by careful technique with accurate needle placement, sterile precautions, and a thorough understanding of the relevant anatomy and contrast patterns on fluoroscopic imaging.
\end{abstract}

Keywords Back pain - Spinal injection - Epidural steroid injection · Lumbar interlaminar epidural $\cdot$ Lumbar transforaminal epidural · Complications · Safety · Risk management

B. S. Goodman $(\bowtie)$ L. W. F. Posecion · S. Mallempati . M. Bayazitoglu

Department of Physical Medicine and Rehabilitation, University of Missouri- Columbia; and the Alabama Orthopedic, Spine and Sports Medicine Associates, 52 Medical park East Drive, Suite 115, Birmingham, AL 35235, USA

e-mail: drspudhead@aol.com

\section{Introduction}

Lumbar epidural steroid injections have been used in the treatment of lumbar radicular pain and other spinal pain syndromes [1-4]. The goal is to deliver steroids and anesthetics into the epidural space around the spinal nerves and other spinal structures. By definition, an interlaminar injection is an approach to the dorsal epidural space going through the space between the lamina of the vertebrae. A transforaminal injection is an approach toward the epidural space via the intervertebral foramen where the spinal nerves exit.

The epidural space surrounds the dural sac and is bounded by the posterior longitudinal ligament anteriorly, the ligamentum flavum and the periosteum of the laminae posteriorly, and the pedicles of the spinal column and the intervertebral foramina containing their neural elements laterally. The space communicates freely with the paravertebral space through the intervertebral foramina. The epidural space contains loose areolar connective tissue, semi-liquid fat, lymphatics, arteries, an extensive plexus of veins, and the spinal nerve roots as they exit the dural sac and pass through the intervertebral foramina [5-7].

The anatomy of the lumbar intervertebral foramen is complicated. It is formed by the pedicles of adjacent vertebrae above and below, the vertebral body of the superior and inferior vertebrae (mostly of the superior vertebra) and intervertebral disc anteriorly, and the articular processes forming the zygapophyseal joint posteriorly. The fascia and psoas muscle form the lateral border, while the medial border contains the dural sleeve $[8,9]$. The foramen allows for the passage of the spinal nerve, the dorsal root ganglion, the segmental spinal artery, the communicating veins between the internal and external plexuses, the recurrent meningeal (sinu-vertebral) nerves, and the transforaminal ligaments $[8,9]$. 
The vascular anatomy of the spinal cord is segmental and based on the embryological development of the body $[10,11]$. An "outside in" simplified algorithm can best describe it: aorta $\rightarrow$ segmental artery (31 pairs (8 cervical, 12 thoracic, 5 lumbar, 5 sacral, 1 coccygeal)) $\rightarrow$ radicular artery (supplies dorsal and ventral nerve roots) $\rightarrow$ radiculopial artery or radiculomedullary $\rightarrow$ posterior (paired) or anterior (single) spinal artery [10, 11]. At the start of embryological development, each segmental artery has a branch that supplies the spinal cord. During development most of these branches regress leaving a few left behind to provide blood for the spinal cord. Of those that remain 4-8 will supply the anterior spinal artery and 10-20 will supply the posterior spinal arteries [10, 11]. The radiculopial artery branches into the posterior spinal arteries. The radiculomedullary artery branches into the anterior spinal artery. Of particular interest is the artery of Adamkiewicz, which is the largest radiculomedullary artery and major supplier of the anterior spinal artery in the lumbar region. The artery enters the spinal canal through a single intervertebral foramen in $85 \%$ of individuals between $\mathrm{T} 9$ and L2 $[12,13]$ and is located $63 \%$ of the time on the left side [14]. Its origin is highly variable [15] and in a minority of people may arise from the lower vertebrae in the lumbar spine [16] and rarely as low as $\mathrm{S} 1$.

To reach the optimal target area for an interlaminar epidural steroid injection (ILESI), a paramedian or midline approach is used through the space between the lamina of the vertebrae. The needle first penetrates the skin, then subcutaneous tissue, paraspinal muscles, and then finally the ligamentum flavum. The "loss of resistance" technique is used to verify penetration into the dorsal epidural space [17].

With an oblique needle approach, the optimal target area for the transforaminal epidural steroid injection (TFESI) is classically described on the posterior surface of the vertebral body, adjacent to the caudal border of the pedicle above the target nerve, opposite the sagittal bisector of the pedicle, also known as the "6 o'clock" position [18] (Figs. 1 and 2). With the more commonly described subpedicular approach, the target point lies within the imaginary "safe triangle" which is formed by the transverse line tangential to the lower margin of the pedicle, a sagittal line tangential to the lateral margin of the pedicle, and a hypotenuse passing obliquely inferiorly and laterally from the inferior medial corner of the pedicle, tangential to the curvature of the pedicle at that corner [18] (Fig. 5b).

Two alternative approaches for TFESI include the retroneural approach and the retrodical approach. The retroneural TFESI approach describes the optimal target area more dorsal in the intervetebral foramen compared to the subpedicular technique [18]. The target typically lies at the intersection of two lines: a longitudinal one between the posterior and middle third of the intervertebral foramen, and a transverse one between the upper and middle third of the intervertebral foramen [18] (Figs. 1 and 2). The retrodiscal TFESI approach places the needle past the lateral surface of the superior articular process (SAP) into the intervertebral foramen; this technique is similar to the needle approach used in discography, but without cannuating the disc [19] (Figs. 1 and 2). In this latter technique, the exiting spinal nerve is lateral rather than medial to the needle as in the subpedicular and retroneural techniques.

The incidence of complications described in the literature with these epidural techniques is low [20, 21]. A thorough understanding of the relevant anatomy and potential pitfalls is necessary to avoid most if not all complications. Complications are related either to the procedure itself-mostly inadvertent placement of the needle off target - or the administration of the corticosteroid or local anesthetic. The purpose of this paper is to review these complications and discuss the potential pitfalls related to these procedures.

\section{Complications}

\section{Infections}

Infections have been reported to occur in 1-2\% of spinal injections [22]. Severe infections are noted to be rare with an incidence of $0.1-0.01 \%$ of all spinal injections [22]. They vary between meningitis [23, 24], epidural abscess [23, 25, 26], osteomyelitis [27, 28], and discitis [29]. Staphylococcus aureus is the most common organism reported to be found. It is believed to be introduced via the skin through needle puncture. It is usually introduced due to poor sterile technique. Undetected and untreated infection can lead to sepsis and spread to other sites through direct contiguous spread or through Batson's plexus [22]. Neurological deficits can occur due to compression from exudate [30]. Patients with immunocompromising conditions such as diabetes are more susceptible to infection and should be followed closely [30].

Infection from gram-negative anaerobes can theoretically occur by unintentional penetration into the intestinal or pelvic cavity [22]. This is particularly easy to do in S1 TFESIs. The needle can unintentionally go through the dorsal foramen and past the ventral foramen entering the pelvic cavity (Fig. 3). In Fig. 3a, the needle is placed using "tunnel vision" into the S1 dorsal foramen. With this technique there may be a lack of bony structure to stop needle advancement. Lateral imaging (Fig. 3b) is critical to check needle depth as it is relatively easy to advance past the ventral foramen and into the pelvic cavity. If this should occur, i.e., the needle depth is miscalculated prior to 

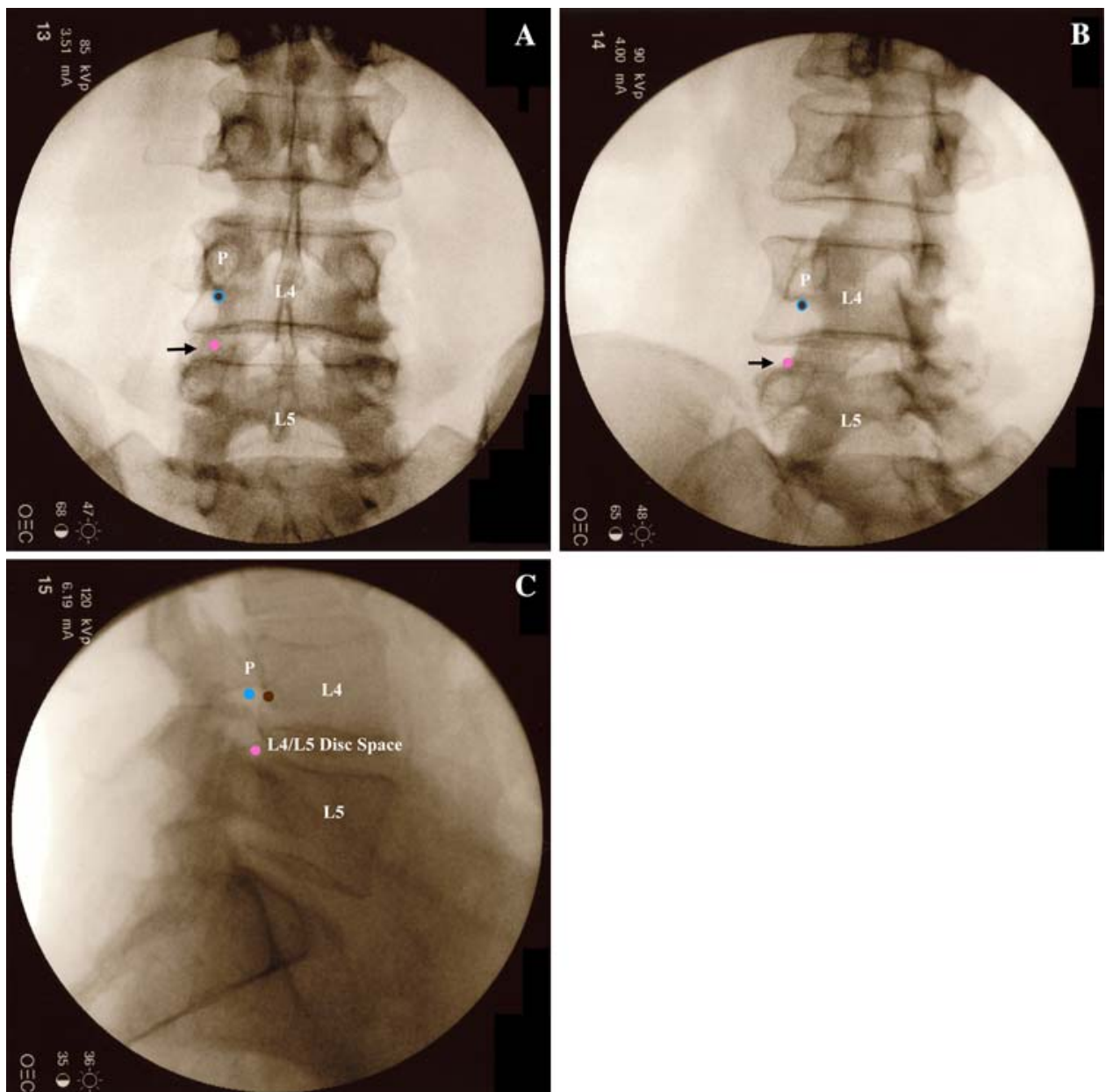

Fig. 1 Fluoroscopic images of the target points for a left L4 TFESI. The brown circle marks the target point for the subpedicular approach, the blue circle for the retroneural approach, and the pink circle for the retrodiscal approach. a AP view. The subpedicular and retroneural approaches have the same target point on AP view. It lies at the bottom of the silhouette of the L4 pedicle (P), but is overlapped by the lateral margin of the L4 lamina [18]. The retrodiscal approach target is lateral to the L5 superior articular process (black arrow) which is not clearly seen on AP imaging.

going to lateral imaging, we recommend removing the needle completely and discarding it from the sterile field rather than repositioning the needle more posteriorly.

In the other lumbar TFESIs there is potential to go past the foramen, along the lateral border of the vertebral body, and into the abdominal cavity potentially piercing the intestinal cavity. At times in the subpedicular or retroneural approaches the SAP obstructs the path to the "6 o'clock" position on the pedicle. The needle is advanced laterally to avoid the SAP. If advanced too far lateral the needle tip can end up along the lateral aspect of the vertebral body instead of more medial into the intervertebral foramen. Lateral imaging helps to further confirm the depth of the needle. If the needle depth goes past the anterior border of the vertebral body, it can potentially pierce the intestinal cavity.

b Left oblique view. The lamina has been rotated medially to expose the target points for all three approaches. The subpedicular and retroneural approaches have the same target point on oblique view. The retrodiscal target point is more easily identified on oblique view (black arrow). c Lateral view. The subpedicular approach target area lies on the back of the L4 vertebral body. The retroneural approach target area lies more dorsal in the L4-L5 foramen underneath the L4 pedicle (P). The retrodiscal approach target area lies just dorsal to the L4-L5 disc space

In the primary author's experience, this rarely occurs. However; one must be alerted to this possibility. Once again, if the needle happened to be too far anterior, we recommend discarding the needle rather than repositioning more posterior and medially to minimize the chance of introducing iatrogenic infection.

\section{Hematomas}

Piercing a vessel is an inherent risk to all injection procedures. Potential complications associated with this are bleeding, the formation of hematomas, and intravascular injection of medication. The potential for bleeding and hematoma formation is increased in patients with a coagulopathy, liver disease, or in patients that take anticoagulant 


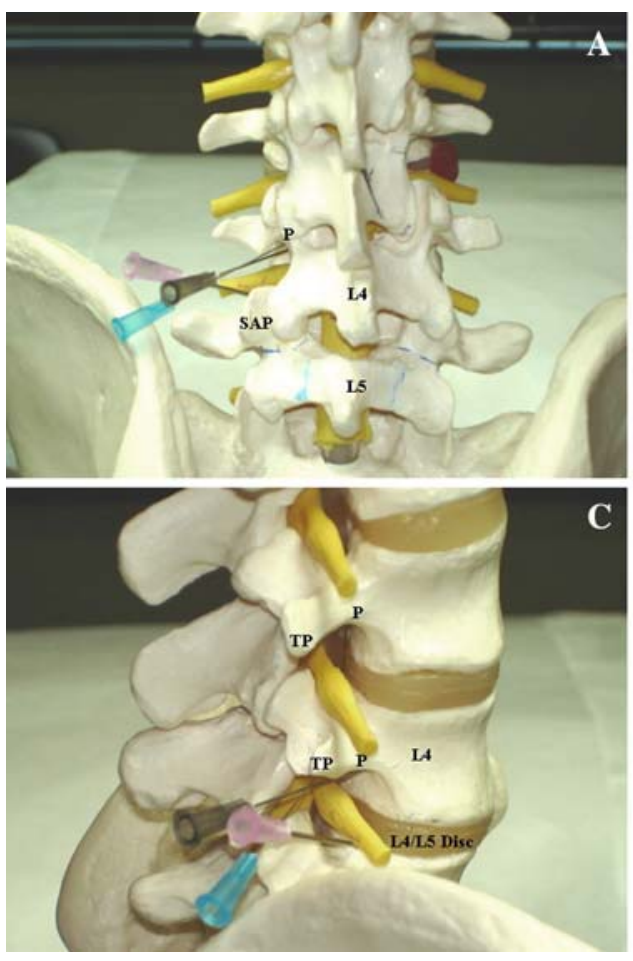

Fig. 2 Model images of needle placement for a left L4 TFESI. The brown needle illustrates the subpedicular approach, the blue needle shows the retroneural approach, and the pink needle depicts the retrodiscal approach. a AP view. The subpedicular and retroneural approaches have the same target point at the " 6 o'clock" position of the L4 pedicle $(\mathrm{P})$. The retrodiscal approach target is lateral to the L5 superior articular process (SAP). b Left oblique view. The subpedicular and retroneural approach have the same target point at

medications such as warfarin or clopidogrel [22, 31]. Damage to the underlying vessels may lead to hematomas that cannot be visualized under traditional fluoroscopy.

Patients use chronic anticoagulant therapy for the prevention of myocardial ischemia or stroke, thromboprophylaxis after surgery, or treatment of acute thromboembolism [32]. The intensity and duration of anticoagulation affect the risk of spontaneous, as well as procedural-related spinal bleeding $[32,33]$. This risk is increased significantly with the use of multiple anticoagulants $[32,33]$. The following guidelines for performing spinal procedures in anticoagulated patients are based on the second American Society of Regional Anesthesia and Pain Medicine (ASRA) Consensus Conference on Neuraxial Anesthesia and Anticoagulation in 2003 [32, 34]. Warfarin therapy should be discontinued 4-5 days before spinal procedures and the international normalized ratio (INR) should be within normal range at the time of the procedure to ensure adequate levels of all vitamin K-dependent factors [32, 34]. Thienopyridine derivatives, e.g., clopidogrel, ticlopidine, should be suspended 7 days and 14 days, respectively, prior to spinal procedures to allow for recovery of primary and secondary platelet aggregation and platelet-fibrinogen binding

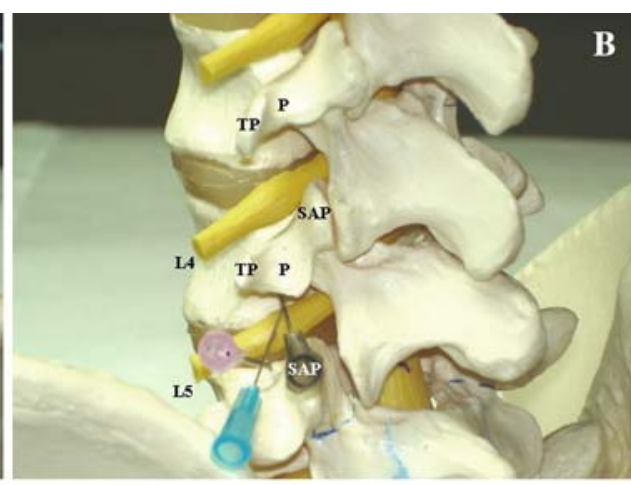

B

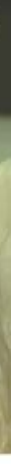

the "6 o'clock" position of the L4 pedicle (P). The retrodiscal approach target is lateral to the L5 SAP (overlapped by the brown needle). $\mathrm{TP}=$ transverse process. c Lateral view. The subpedicular approach target area lies on the back of the L4 vertebral body. The retroneural approach target area lies more dorsal in the L4-L5 foramen underneath the L4 pedicle $(\mathrm{P})$. The retrodiscal approach target area lies just dorsal to the L4-L5 disc. TP $=$ transverse process

$[32,34]$. Aspirin and non-steroidal antiinflammatory drugs (NSAIDs) have not been found to have any contraindications for spinal procedures [32, 34, 35]. Low-molecular weight heparin (LMWH) should be held for at least $12 \mathrm{~h}$ before the procedure in thromboprophylactic dosing and at least $24 \mathrm{~h}$ in therapeutic dosing [32, 34].

The incidence of epidural hematoma is approximated to be less than 1 in 150,000 epidurals [34]. The actual incidence of neurologic dysfunction resulting from hemorrhagic complications is unknown [34]. Epidural hematomas can lead to compression of the spinal nerve or nerves causing irreversible damage [36]. Nerve injury may be minimized by evacuation of the hematoma within $24 \mathrm{~h}$ of the first symptoms [37]. In the lead author's experience, an epidural hematoma was incidentally discovered while performing an ILESI (Fig. 4). The patient had a myelogram 2 weeks prior to the epidural injection at a different facility, which presumably led to the unrecognized epidural hematoma. During the ILESI the needle was unintentionally placed in the superior aspect of the hematoma. Upon injection of contrast, an unusual dye spread occurred. Because the pattern of spread could not be definitively distinguished, the ILESI was aborted and a TFESI was 

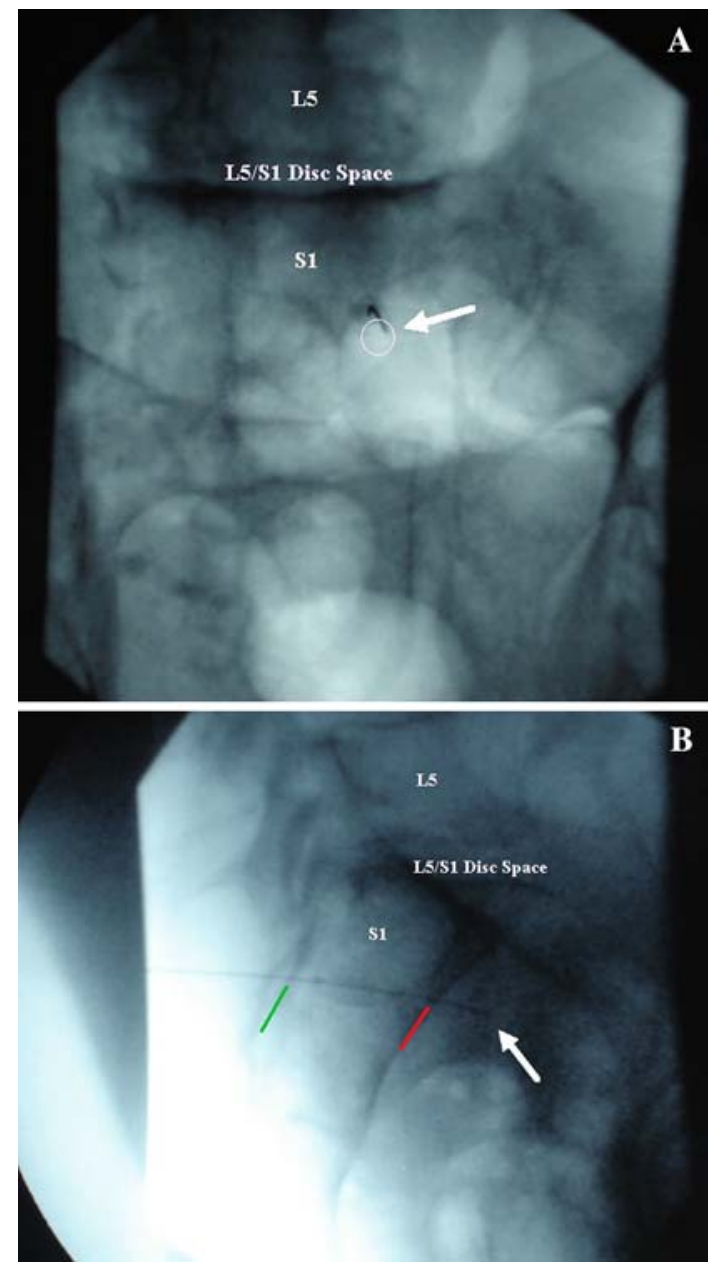

Fig. 3 a AP image of needle in the right $\mathrm{S} 1$ foramen (white circle) of a cadaveric specimen. White arrow shows needle tip. b Lateral image depicting the needle penetrating into the pelvic cavity through the S1 ventral foramen. Green line delineating the dorsal sacral border. Red line delineating the ventral sacral border. White arrow illustrating the tip of the needle in the pelvic cavity of a cadaveric specimen

performed instead. Later, a magnetic resonance imaging (MRI) of the lumbar spine was obtained demonstrating the epidural hematoma. The contrast spread, in essence, is an epidural hematogram. Fortunately, images were saved documenting that the hematoma must have existed prior to the epidural injection rather than because of the epidural injection. Additionally, by not injecting further, the ILESI did not increase volume to the mass.

\section{Intravascular injections}

Recognition of intravascular uptake and contrast spread is needed to avoid inadvertent injection of medications into the vascularity. Furman et al. [38] reported an overall rate of $11.2 \%$ for intravascular injection for lumbosacral

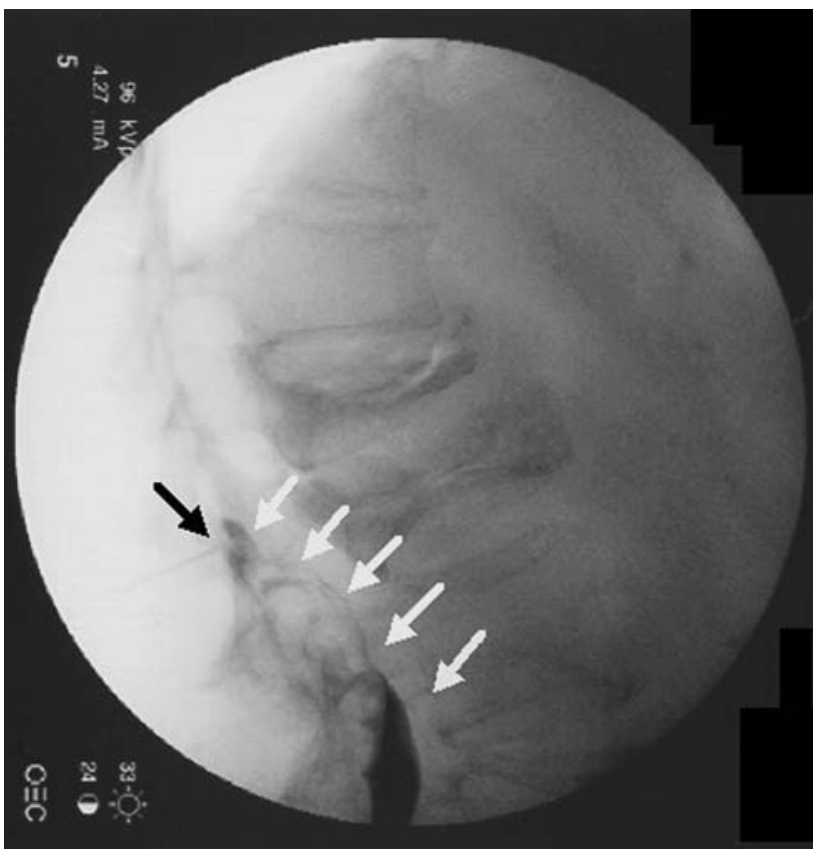

Fig. 4 Interlaminar epidural depicting epidural hematomagram (white arrows). Black arrow placed to highlight needle location

TFESIs. TFESIs at the S1 level had an intravascular injection rate of $21.3 \%$, compared with $8.1 \%$ for all lumbar injections. With ILESIs, intravascular uptake is more common with needle placement in the lateral portion of the spinal canal than midline because the internal posterior vertebral venous plexus within the epidural space is located predominantly dorsolaterally [39]. The incidence of intravascular uptake with ILESI is reported by Sullivan et al. [40] to be $1.9 \%$. Using a blood "flash back" or blood aspiration to predict an intravascular injection was not reliable. It is postulated that there is not enough pressure in the venous system to result in spontaneous blood flow into the needle hub. However, during contrast or medication injection, there is enough positive pressure to keep these smaller vessels distended, resulting in intravascular injection [38, 40,41]. Therefore contrast injection is essential to minimize subsequent intravascular injection of medications [38]. Intravascular uptake is twice as likely to occur in patients over 50 years of age [40].

In the studies that reported the incidence of intravascular injections, no complications or adverse affects were found from intravascular, presumably intravenous, injection of contrast, steroid, or local anesthetic. [38, 40, 41]. Theoretically, patients may experience temporary adverse reactions from systemic uptake of local anesthetics. These symptoms include a range of minor symptoms: dizziness, tinnitus, disorientation, muscle twitching, and metallic taste to major symptoms: seizures, unconsciousness, and coma. The severity of symptoms depends on the amount of 
Fig. 5 a Right oblique image with attention to the L4/L5 interspace after classic subpedicular TFESIs. (Needles placed underneath the right L3, L4, L5, and S1 pedicles). Black arrow highlighting exiting right L4 spinal nerve. b Same image. White triangle illustrating "safe triangle" target area for subpedicular and retroneural approaches for TFESI. Black triangle illustrating target area for retrodiscal approach for TFESI
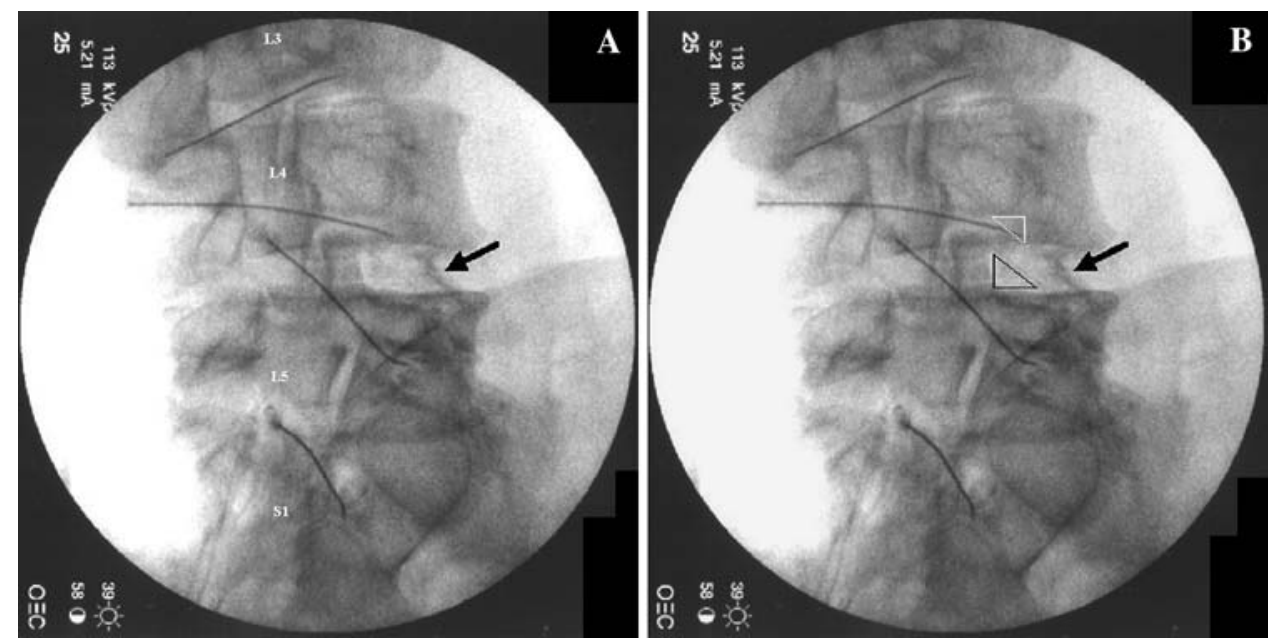

local anesthetic used [42]. Intravenous uptake of medications may also diminish the efficacy of epidural injections [38]. For example, when performing medial branch blocks, Dreyfuss found a $50 \%$ false negative rate with intravascular uptake even when the needle was repositioned such that intravascular uptake was eliminated [43].

While intravenous penetration is relatively common with minimal sequelae, intraarterial penetration and subsequent injection of particulate steroids can lead to a catastrophic outcome. This occurs via the artery of Adamkiewicz which travels with the nerve root through the neural foramen and supplies the anterior spinal artery. This can lead to a spinal infarction and paraplegia [12, 13, 44]. Use of contrast before injection helps to avoid this complication by being able to distinguish an epidural spread versus an intravascular spread. Since the artery enters the spinal canal $85 \%$ of the time between T9 and L2 [12, 13] and is located on the left side $63 \%$ of the time [14], heightened precaution should be taken for TFESIs at these levels. Houten et al. [12] reported on three cases of paraplegia after lumbosacral nerve block believed to be the result of inadvertent intraarterial injection and an unusually low origin of the artery of Adamkiewicz. In each instance, penetration of the vessel was undetected, i.e., no blood flashes back. In two procedures the needles were placed transforaminally, one at L3-4 on the left and one at L3-4 on the right, and in the third the tip of the needle was placed immediately lateral to the S1 nerve root [12].

Some injectionists utilize digital subtraction angiography (DSA) to help distinguish intraarterial injection of contrast and thus avoid further injection of local anesthetic or steroids into the arterial system. DSA is a computer-assisted X-ray technique that separates and removes images of bone and soft tissue to permit visualization of vascular structures. DSA, however, is not routinely available in most facilities. In our practice, we utilize dexamethasone sodium phosphate for all TFESIs. There has yet to be any reported complications with this preparation. This may be due to its non-particulate nature [45]. Derby et al. [45] found that dexamethasone sodium phosphate particle size is approximately 10 times smaller than red blood cells, the particles do not appear to aggregate, and they have the lowest density compared to other commonly used steroid preparations (e.g., triamcinolone acetonide, methylprednisolone acetate, betamethasone sodium phosphate, and betamethasone acetate). Theoretically, these attributes should lower the risk of embolic infarcts or prevent them from occurring after intraarterial injection [45]. There may be a trade off in the efficacy of this non-particulate steroid in that it has a shorter duration of action. Dreyfuss et al. [46] reported that the effectiveness of dexamethasone was slightly less than that of triamcinolone, but the difference was neither statistically nor clinically significant. Since particulate steroids have been associated with spinal cord infarctions $[12,44$, 47], perhaps a safer yet less efficacious non-particulate steroid should be used [46].

In the primary author's experience, there is a theoretical advantage to the retroneural and retrodiscal techniques in TFESIs in terms of vascular anatomy. Since the optimal target area places the tip of the needle more dorsal in the intervertebral foramen, there is less risk of pinning a spinal artery against the posterior wall of the vertebral body or injecting into it.

\section{Nerve trauma}

Direct trauma to a spinal nerve or dorsal root ganglion by a needle is another complication of inadvertent needle placement, especially when performing TFESIs. Severe pain is caused with this trauma so it is important not to over sedate the patient so that this complication is not masked. If severe pain accompanies needle placement, then the needle should be slightly withdrawn and its position reassessed [18]. In the first author's experience, injecting a small volume of local anesthetic while repositioning the needle 
slightly often quickly alleviates the discomfort. Caution should be used such that the anesthetic is not forcibly injected. Furthermore, staying more posterior in the foramen, i.e., the retroneural approach may help avoid nerve trauma. The retrodiscal approach may also reduce the incidence of nerve trauma relative to the classic subpedicular approach in that the nerve may rest further from the target point (Fig. 5). The drawback to the retrodiscal approach may be a less recognizable epidural spread of contrast compared to the other classic approaches. These phenomena, to our knowledge, have not been formally reported or studied.

\section{Dural puncture}

Inadvertent spinal dural puncture during ILESIs and TFESIs with subsequent entry into the subdural and subarachnoid space can also occur. Dural puncture can occur with ILESIs when the needle is advanced beyond the dorsal epidural space, thereby entering the central spinal canal. Dural puncture has also been reported with TFESIs via penetration of the dural sleeve that surrounds the exiting spinal nerves [48]. Cerebral spinal fluid (CSF) flashback is typically used to recognize the complication of a dural puncture. Recognition of epidural contrast spread versus subdural and subarachnoid contrast spread patterns is essential because dural penetration may not be accompanied by CSF flashback. This is especially true when performing TFESIs [48]. Figure 6 illustrates dural puncture during a TFESI with subdural spread of contrast in a previously reported case study [48].

If local anesthetics are injected intrathecally, blockade of neural elements can result in central canal, cauda equina, and conus medularis syndromes depending on the level of penetration and blockade. Other reported complications with intrathecal injections of medications include persistent parathesias, arachnoiditis, and meningitis. Temporary respiratory depression, ascending weakness/sensory loss, apnea, and unconsciousness may also occur and are felt to be related to ascending subdural spread of anesthetics $[26$, 48-52]. The amount of local anesthetic typically used in lumbar epidurals $(6-8 \mathrm{ml})$ usually is not sufficient enough to cause respiratory depression. However, a larger volume within the subdural space can ascend rapidly in a cephalad direction causing serious cardiovascular and respiratory effects [48, 53, 54]. Chauhan et al. [53] describe a case of unintentional combined epidural and subdural block while attempting to perform an epidural block for transurethral resection of the prostate. A $20 \mathrm{ml}$ injection of $1.5 \%$ lidocaine and $0.5 \%$ bupivacaine resulted in aphonia and respiratory paralysis requiring endotracheal intubation and controlled ventilation for $3 \mathrm{~h}$. The potential for such serious complications heightens the operator's need to
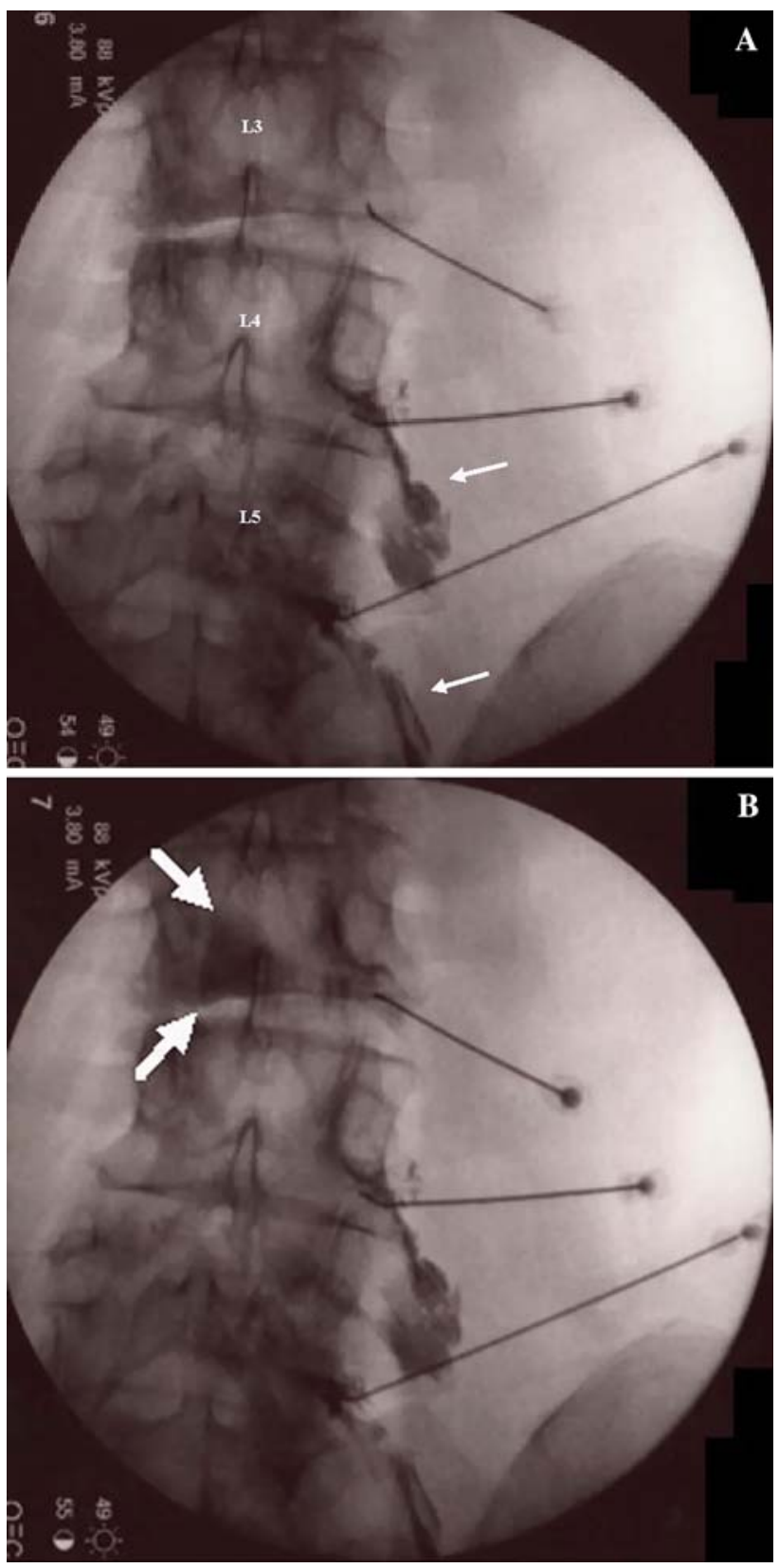

Fig. 6 a AP scout image of right L3 transforaminal needle placement. Right L4 and right L5 transforaminal epiduragrams are illustrated (white arrows) [43]. b Subdural injection of contrast at L3 (white arrows) [43]

recognize both subarachnoid and subdural contrast spread patterns.

Dural punctures may also lead to spinal headache. These headaches are typically severe, dull, non-throbbing pain, and fronto-occipital in location, that aggravate in the upright position and diminish in the supine position. CSF can leak through the dural puncture leading to a loss of CSF pressure and a drop in brain volume. The mechanism producing the headache is unclear, though two theories do exist. First, in an upright position there is tension on the 
meninges and other intracranial structures which have nociceptors causing pain [55]. Secondly, it is thought that in the upright position more CSF is forced to exit the dural puncture and the body compensates by venodilation causing pain related to vascular distension [55].

\section{Air embolism}

When using air with the "loss of resistance" technique in ILESI to identify the epidural space, there are risks with injecting too much air. One possibility is placing the needle both epidurally and intravascularly without a blood flash back. A subsequent injection of air can then cause an air embolism to develop within the vasculature. MacLean and Bachman [56] depicted a case of syncope, arrhythmia, cardiac ischemia, and neurologic deficit after a spinal epidural injection which caused an arterial gas embolus. There is also the possibility of injecting excessive air epidurally to mimic a mass lesion. Ammirati and Perino [57] documented a case of new neurological symptoms occurring immediately after a lumbar epidural. An MRI revealed trapped air displacing the dural sac. Attention should be paid to the amount of air being injected during epidurals to limit this problem.

\section{Disc entry}

ILESI and TFESI can also spread medications to structures outside of the intended epidural target, especially with aberrant or pathological anatomy. Finn and Case [58], for example, recounted a case of disc entry as a complication of transforaminal injection. Though this occurrence is rare, we do not consider this a complication because anecdotally we have found excellent outcomes with injecting around the spinal nerve and into the disc herniation simultaneously. Figure 7 illustrates intradiscal spread of contrast and subsequent medications with a TFESI.

\section{Bladder complications}

Urinary complications occur more commonly in elderly males, multiparous females, and patients who had inguinal and perineal surgery [22]. The administration of local anesthetics around the lumbar and sacral nerve roots has a higher incidence of urinary retention [59]. Epidural block of S2-S4 root fibers decreases urinary bladder tone and inhibits the voiding reflex [60].

\section{Radiation exposure}

The risk of fluoroscopic exposure to the patient is minimal for one or several isolated fluoroscopic guided epidurals [22]. A properly calibrated digital fluoroscopy machine delivers a low dose of ionizing radiation. It is the

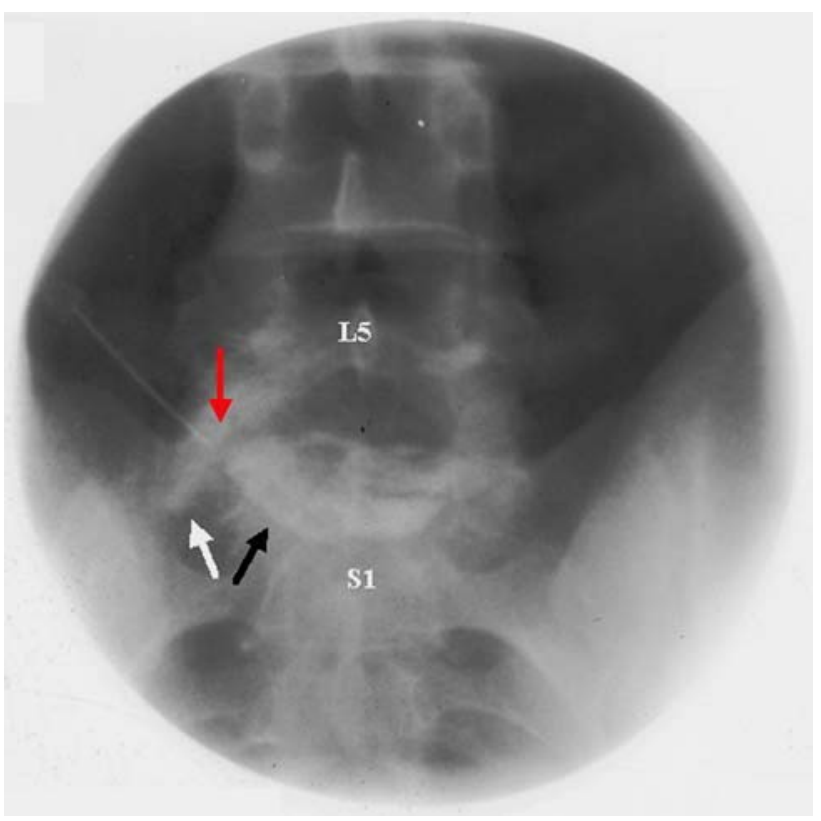

Fig. 7 AP image of a left L5 transforaminal sequestered disc injection. Contrast spread along the left L5 spinal nerve (white arrow) and into the L5/S1 disc space (black arrow). Red arrow depicting needle tip placement

cumulative exposure to the physician, nurses, radiology technicians, and anyone else that is routinely involved in these procedures that are at risk for complications [61-63]. Possible complications are cancer, sterility, cataract development, bone marrow suppression, and skin desquamation. The annual maximum target area/organ permissible radiation doses are as follows: thyroid 50 rem (roentgen equivalent in man), extremities $50 \mathrm{rem}$, lens of the eye $15 \mathrm{rem}$, gonads 50 rem, whole body 5 rem [64]. Manchikanti et al. documented the radiation exposure to clinicians after fluoroscopic interventional spinal procedures in 1,000 consecutive patients. The radiation exposure to the physician on the outside of the lead apron over the upper chest was 1,345 mrem for the entire period. Exposure for 2,000 procedures extrapolated to 2,690 mrem outside the apron which is within the annual limits of exposure [63].

There are many ways to limit the amount of exposure to the patient, physician, and staff. The National Council on Radiation and Measurements (NCRP) endorse the concept of ALARA (as low as reasonably achievable), which is based on the premise that all radiation exposures that can be prevented should be prevented [64]. Fishman et al. [65] described three major ways to reduce clinician radiation exposure: (1) maximize the distance from the radiation source, (2) minimize the time of radiation, (3) use protective shielding devices.

Radiation dissipates at the inverse square of the distance from the fluoroscopy tube. Therefore, standing six feet or 
more from the tube reduces excessive exposure [59-63]. The fluoroscopy anode should be kept under the procedure table thus the patient absorbs the bulk of the directed radiation [63, 65]. Intermittent fluoroscopy, last image hold, and pulsed fluoroscopy are ways to reduce radiation times [66]. In the lead author's experience, good technique and a clear understanding of the relevant anatomy and contrast patterns also minimizes radiation exposure by reducing the time to set up the images and perform the injections. According to Fishman, Manchikanti, et al. [63, 65], all staff in the procedure room should at least wear a lead apron and thyroid shield to decrease radiation exposure. Radiation dosimetry badges should be worn to monitor exposure [63, 65]. Manchikanti et al. showed that in 1,000 consecutive procedures the radiation exposure inside the thyroid shield and lead apron was 0 mrem.

\section{Medication complications}

Medication complications are rare with the drugs used in lumbar spinal injections. The most common local anesthetics used are lidocaine and bupivacaine. Their primary route of action is reversibly blocking the sodium channels in nerve and muscle membranes [67]. Although very uncommon, physicians must be aware of possible allergy to local anesthetic or its preservative, which occurs within $2 \mathrm{~h}$ after epidural injection but has been known to happen up to 6 h later $[68,69]$. Inadvertent intrathecal injection of local anesthetic can result in spinal anesthesia as previously addressed.

Corticosteroids inherently have side effects: dizziness, headache, facial erythema, transient hypotension and hypertension, gastritis, mood swings, pruritus, insomnia, and menstrual irregularities [70]. Prolonged therapy with corticosteroids may result in suppression of the hypothalamus-pituitary-adrenal (HPA) axis by inhibiting adrenocorticotropic hormone (ACTH) [70]. Rarely can a Cushingoid syndrome develop with epidural steroid injection [70]. Diabetics can have a temporary elevation of blood sugar levels up to 3-7 days. Patients with congestive heart failure should be aware of possible fluid retention due to corticosteroids, although extremely uncommon [70]. No studies show a relationship between epidural steroid injection and osteoporosis or avascular necrosis [70]. Inadvertent intravascular injection of particulate corticosteroids can cause occlusion of small end arteries as discussed above. All in all corticosteroid use in epidural injections is safe when administered carefully.

Contrast media are usually non-ionic radiocontrast agents with a more physiologic osmolality and less free iodine. However, hypersensitive reactions are still possible and would be evident within the first few minutes after injection. Anaphylactic reactions involve IgE-mediated release of vasoactive substances after exposure to an antigen to which there has been previous exposure and sensitization $[71,72]$. A true IgE type I hypersensitivity is rare and only in severe cases [72]. Anaphylactoid reactions occur through a non-immune mechanism. They are pseudoallergic reactions that are caused by the direct release of histamine and other mediators from basophils and mast cells $[71,72]$. Clinically, these two reactions are indistinguishable from one another. If an allergy is suspected then pretreatment with antihistamines and corticosteroids should be considered $[72,73]$ or gadolinium should be used as an alternative [74]. These reactions are highly unusual in extravascular procedures [75].

\section{Conclusion}

Complications from lumbar epidural injections are extremely rare. Most if not all complications can be avoided by careful technique with accurate needle placement, sterile precautions, and a thorough understanding of the relevant anatomy and contrast patterns on fluoroscopic imaging.

\section{References}

1. Boswell MV, Trescott AM, Datta S, American Society of Interventional Pain Physicians, et al. Interventional techniques: evidence-based practice guidelines in the management of chronic spinal pain. Pain Physician. 2007;10:7-111.

2. Lutz GE, Vad B, Wisneski RJ. Fluoroscopic transforaminal lumbar epidural steroids: an outcome study. Arch Phys Med Rehabil. 1998;79:1362-6.

3. Vad V, Bhat A, Lutz G. Transforaminal epidural steroid injections in lumbosacral radiculopathy: a prospective randomized study. Spine. 2002;27:11-6.

4. Riew KD, Yin Y, Gilula L, et al. The effect of nerve-root injections on the need for operative treatment of lumbar radicular pain. A prospective, randomized, controlled, double-blind study. J Bone Joint Am. 2000;82A:1589-93.

5. Westbrook JL, Renowden SA, Carrie LE. Study of the anatomy of the extradural region using magnetic resonance imaging. Br J Anaesth. 1993;71:495-8.

6. Hogan QH. Lumbar epidural anatomy. A new look by cryomicrotome section. Anesthesiology. 1991;75:767-75.

7. Hogan QH. Epidural anatomy examined by cryomicrotome section. Influence of age, vertebral level, and disease. Reg Anesth. 1996;21:395-406.

8. Gilchrist RV, Slipman CW, Bhagia SM. Anatomy of the Intervertebral Foramen. Pain Physician. 2002;5:372-8.

9. Bogduk N. Clinical anatomy of the lumbar spine and sacrum. 4th ed. London: Churchill Livingstone; 2005.

10. Mathis JM. Image-guided spine interventions. New York: Springer-Verlag; 2004.

11. Krauss WE. Vascular anatomy of the spinal cord. Neurosurg Clin N Am. 1999;16:333-45.

12. Houten JK, Errico TJ. Paraplegia after lumbosacral nerve root block: report of three cases. Spine J. 2002;2:70-5.

13. Conners J, Wojack J. Interventional neuroradiology: strategies and practical techniques. Philadelphia: WB Saunders Company; 1999. 
14. Boll DT, Bulow H, Blackham KA, et al. MDCT angiography of the spinal vasculature and the artery of Adamkiewicz. AJR Am J Roentgenol. 2006;187:1054-60.

15. Gillilan L. The arterial blood supply of the human spinal cord. J Comp Neurol. 1958;110:75-103.

16. Tveten L. Spinal cord vascularity. Acta Radiol Diagn (Stockh). 1976;1F:1-16.

17. Botwin KP, Natalicchio J, Hanna A. Fluoroscopic guided lumbar interlaminar epidural injections: a prospective evaluation of epidurography contrast patterns and anatomical review of the epidural space. Pain Physician. 2004;7:77-80.

18. Bogduk N. Practice guidelines for spinal diagnostic and treatment procedures. ISIS. 1st ed. San Francisco: International Spine Intervention Society; 2004.

19. Jasper JF. Lumbar retrodiscal transforaminal injection. Pain Physician. 2007;10:501-10.

20. Botwin KP, Gruber RD, Bouchlas CG, et al. Complications of fluoroscopically guided transforaminal lumbar epidural injections. Arch Phys Med Rehabil. 2000;81:1045-50.

21. Huston CW, Slipman CW, Garmin C. Complications and side effects of cervical and lumbosacral selective nerve root injections. Arch Phys Med Rehabil. 2005;86:277-83.

22. Windsor RE, Storm S, Sugar R. Prevention and management of complications from common spinal injections. Pain Physician. 2003;6:473-83.

23. Hooten WM, Kinney MO, Huntoon MA. Epidural abscess and meningitis after epidural corticosteroid injection. Mayo Clin Proc. 2004;79:682-6.

24. Gutknecht DR. Chemical meningitis following epidural injections of corticosteroids. Am J Med. 1987;82:570.

25. Kabbara A, Rosenberg SK, Untal C. Methicillin-resistant Staphylococcus aureus epidural abscess after transforaminal epidural steroid injection. Pain Physician. 2004;7:269-72.

26. Abram SE, O'Connor TC. Complications associated with epidural steroid injections. Reg Anesth. 1996;21:149-62.

27. Tham EJ, Stoodley MA, Macintyre PE, et al. Back pain following postoperative epidural analgesia: An indicator of possible infection. Anesth Intensive Care. 1997;25:297-301.

28. Yue WM, Tan SB. Distant skip level discitis and vertebral osteomyelitis after caudal epidural injection: a case report of a rare complication of epidural injections. Spine. 2003;28:E209-11.

29. Hooten WM, Mizerak A, Carns PE. Discitis after lumbar epidural corticosteroid injection: a case report and analysis of the case report literature. Pain Med. 2006;7:46-51.

30. Rigamonti D, Liem L, Sampath P, et al. Spinal epidural abscess: contemporary trends in etiology, evaluation, and management. Surg Neurol. 1999;52:189-96.

31. Landefeld CS, Beyth RJ. Anticoagulant-related bleeding: clinical epidemiology, prediction, and prevention. Am J Med. 1993;95: 315-28.

32. Layton KF, Kallmes DF, Horlocker TT. Recommendations for anticoagulated patients undergoing image-guided spinal procedures. AJNR Am J Neuroradiol. 2006;27:468-70.

33. Stafford-Smith M. Impaired haemostasis and regional anaesthesia. Can J Anaesth. 1996;43:R129-41.

34. Horlocker TT, Wedel DJ, Benzon H, et al. Regional anesthesia in the anticoagulated patient: defining the risks (the second ASRA Consensus Conference on Neuraxial Anesthesia and Anticoagulation). Reg Anesth Pain Med. 2003;28:172-97.

35. Horlocker TT, Bajwa ZH, Ashraf Z, et al. Risk assessment of hemorrhagic complications associated with nonsteroidal anti-inflammatory medications in ambulatory pain clinic patients undergoing epidural steroid injection. Anesth Analg. 2002;95: 1691-7.

36. Stoll A, Sanchez M. Epidural hematoma after epidural block: implications for its use in pain management. Surg Neurol. 2002;57:235-40.
37. Lawton MT, Porter RW, Heiserman JE. Surgical management of spinal epidural hematoma: relationship between surgical timing and neurological outcome. J Neurosurg. 1995;83:1-7.

38. Furman M, Giovanniello M, O’Brien E. Incidence of intravascular penetration in transforaminal lumbosacral epidural steroid injections. Spine. 2000;25:2628-32.

39. Carpenter M. Blood supply of the central nervous system. In: Satterfield T, editor. Core text of neuroanatomy. 4th ed. Baltimore: Williams \& Wilkins; 1991.

40. Sullivan WJ, Willick SE, Chira-Adisai W. Incidence of intravascular uptake in lumbar spinal injection procedures. Spine. 2000;25:481-6.

41. Goodman BS, Lincoln CE, Deshpande KK. Incidence of intravascular uptake during fluoroscopically guided lumbar disc injections: a prospective observational study. Pain Physician. 2005;8:263-6.

42. Mulroy MF. Systemic toxicity and cardiotoxicity from local anesthetics: incidence and preventative measures. Reg Anesth Pain Med. 2002;27:556-61.

43. Dreyfuss P, Halbrook B, Pauza K. Efficacy and validity of radiofrequency neurotomy for chronic lumbar zygapophysial joint pain. Spine. 2000;25:1270-7.

44. Huntoon MA, Martin DP. Paralysis after transforaminal epidural injection and previous spinal surgery. Reg Anesth Pain Med. 2004;29:494-5.

45. Derby R, Lee SH, Date ES, et al. Size and aggregation of corticosteroids used for epidural injections. Pain Med. 2008;9:227-34.

46. Dreyfuss P, Baker R, Bogduk N. Comparative effectiveness of cervical transforaminal injections with particulate and nonparticulate corticosteroid preparations for cervical radicular pain. Pain Med. 2006;7:237-42.

47. Tiso RL, Cutler T, Catania JA, et al. Adverse central nervous system sequelae after selective transforaminal block: the role of corticosteroids. Spine J. 2004;4:468-74.

48. Goodman BS, Bayazitoglu M, Mallempati S, et al. Dural puncture and subdural injection: a complication of lumbar transforaminal epidural injections. Pain Physician. 2007;10:697-705.

49. Singh B, Sharma P. Subdural block complicating spinal anesthesia? Anesth Analg. 2002;94:1007-9.

50. Hodgson PS, Neal JM, Pollock JE, et al. The neurotoxicity of drugs given intrathecally (spinal). Anesth Analg. 1999;88:797809.

51. Horlocker TT, McGregor DG, Matsuhige DK, et al. A retrospective review of 4767 consecutive spinal anesthetics: central nervous system complications. Perioperative Outcomes Group. Anesth Analg. 1997;84:578-84.

52. Collier CB. Accidental subdural injection during attempted lumbar epidural block may present as a failed or inadequate block: radiographic evidence. Reg Anesth Pain Med. 2004;29:45-51.

53. Chauhan S, Gaur A, Tripathi M, et al. Unintentional combined epidural and subdural block. Case report. Reg Anesth. 1995;20:249-51.

54. Mizuyama K, Dohi S. An accidental subdural injection of a local anaesthetic resulting in respiratory depression. Can $\mathrm{J}$ Anaesth. 1993;40:83-4.

55. Turnbull DK, Shepherd DB. Post-dural puncture headache: pathogenesis, prevention and treatment. $\mathrm{Br} \mathrm{J}$ Anaesth. 2003;91:718-29.

56. MacLean CA, Bachman DT. Documented arterial gas embolism after spinal epidural injection. Ann Emerg Med. 2001;38:592-5.

57. Ammirati M, Perino F. Symptomatic air trapped in the spine after lumbar epidural corticosteroid injection. Case report. J Neurosurg Spine. 2006;5:359-61.

58. Finn K, Case J. Disk entry: a complication of transforaminal epidural injection-a case report. Arch Phys Med Rehabil. 2005;86:1489-91. 
59. Armitage EN. Lumbar and thoracic epidural. In: Wildsmith JAW, Armitage EN, editors. Principles and practice of regional anesthesia. New York: Churchill Livingstone; 1987.

60. Morgan GE, Mikhail MS, Murray MJ. Clinical anesthesiology. 4th ed. New York: Lange Medical Books/McGraw-Hill Medical Publishing Division; 2006.

61. Botwin KP, Thomas S, Gruber RD. Radiation exposure of the spinal interventionalist performing fluoroscopically guided lumbar transforaminal epidural steroid injections. Arch Phys Med Rehabil. 2002;83:697-701.

62. Manchikanti L, Cash KA, Moss TL, et al. Radiation exposure to the physician in interventional pain management. Pain Physician. 2002;5:385-93.

63. Manchikanti L, Cash KA, Moss TL, et al. Effectiveness of protective measures in reducing risk of radiation in interventional pain management: a prospective evaluation. Pain Physician. 2003;6:301-5.

64. National Council on Radiation Protection and Measurements (NCRP). Report No. 116 Limitation of exposure to ionizing radiation. Bethesda, MD: NCRP Publications; 1993.

65. Fishman SM, Smith H, Meleger A, et al. Radiation safety in pain medicine. Reg Anesth Pain Med. 2002;27:296-305.

66. Mahesh M. Patient radiation exposure issues. Radiographics. 2001;21:1033-45.

67. Fozzard HA, Lee PJ, Lipkind GM. Mechanism of local anesthetic drug action on voltage-gated sodium channels. Curr Pharm Des. 2005;11:2671-86.
68. Simon DL, Kunz RD, German JD, et al. Allergic or pseudoallergic reaction following epidural steroid deposition and skin testing. Reg Anesth. 1989;14:253-5.

69. Caron AB. Allergy to multiple local anesthetics. Allergy Asthma Proc. 2007;28:600-1.

70. Manchilanti L. Role of neuraxial steroids in interventional pain management. Pain Physician. 2002;5:182-99.

71. Mertes PM, Laxenaire MC, Alla F, Groupe d'Etudes des Réactions Anaphylactoïdes Peranesthésiques. Anaphylactic and anaphylactoid reactions occurring during anesthesia in France in 1999-2000. Anesthesiology. 2003;99:536-45.

72. Meth MJ, Maibach HL. Current understanding of contrast media reactions and implications for clinical management. Drug Saf. 2006;29:133-41.

73. Namasivayam S, Kalra MK, Torres WE, et al. Adverse reactions to intravenous iodinated contrast media: a primer for radiologists. Emerg Radiol. 2006;12:210-5.

74. Safriel Y, Ali M, Hayt M, et al. Gadolinium use in spine procedures for patients with allergy to iodinated contrastexperience of 127 procedures. AJNR Am J Neuroradiol. 2006;27: 1194-7.

75. Cohan RH, Matsumoto JS, Quagliano PV. Manual on contrast media. 4th ed. Reston, VA: American College of Radiology; 1998. 